\title{
COVID-19: molecular diagnostics overview
}

\author{
Marlin Touma ${ }^{1}$
}

Received: 1 May 2020 / Revised: 24 May 2020 / Accepted: 26 May 2020 / Published online: 13 June 2020

(C) Springer-Verlag GmbH Germany, part of Springer Nature 2020

\begin{abstract}
The last day of 2019 delivered the first report to the World Health Organization (WHO) about a group of cases of pneumonia of unknown etiology in Wuhan, China. Subsequent investigations identified the new comer, a novel coronavirus related to severe acute respiratory syndrome coronavirus (SARS-CoV) and thus was termed as SARS-CoV-2. Being very contagious, the new virus led the era of "COVID-19" which is the acronym of "coronavirus disease 2019," evoking an imminent threat to global health security with unprecedented devastating challenges to human kind. In this article, we provide a molecular overview on the SARS-CoV-2 virus and summarize tremendous efforts that have been made to develop a rapid confirmatory diagnostic test for COVID-19. The diagnostic performances of the available tests are analyzed based on the best current information from the early research.
\end{abstract}

Keywords COVID-19 $\cdot$ SARS-CoV-2 $\cdot$ Coronavirus

\section{Introduction}

The dynamics that underlie the rapid spread of COVID-19 are currently unknown [1-4]. However, the lack of vaccine and herd immunity and the paucity of knowledge concerning human-to-human transmission at the beginning of the outbreak are potentially important contributing factors $[5,6]$. Remarkably, many patients with COVID-19 may present with non-specific symptoms such as fever, cough and sore throat, while others may remain asymptomatic. The latter subjects are thought to be significant sources to propagate infection in the population [4-6]. At the time of this report (CDC's update on May 16, 2020), the case count of COVID-19 in the USA stands at 1,470,000 cases, including 88,237 deaths, indicating a mortality rate of $6 \%$. The total count of cases worldwide stands at 4,560,000 cases, including 308,000 deaths, indicating a mortality rate of $6.7 \%$ [5]. We refer the readers to the reference citation [5]. https://www.google.com/search?sxsrf= ALeKk03CS16RzZv2-d4WNLT2UeCH7MSOMA: $1589689664696 \& q=$ covid+19+case+count+worldwide for timely update of the case count, regional and worldwide.

Marlin Touma

mtouma@mednet.ucla.edu

1 Department of Pediatrics, David Geffen School of Medicine, University of California, Los Angeles, CA, USA
Holistic approaches interrogating the principles of early diagnosis, early isolation, and early prevention have been implemented at the personal, national, and international levels. Several governments around the globe have activated a national emergency alert to establish infection prevention measures to contain the propagating effects of the disease. Healthcare organizations and medical centers provide dynamically updated guidelines to best alleviate the impact of the pandemic. Medical personnel exchange knowledge about the mechanisms of transmission, the clinical manifestations, and the therapeutic approaches. Clinical diagnostics and research laboratories around the world are at work to understand disease mechanisms, to optimize diagnostic tests, and to develop vaccines for prevention. However, despite incredible efforts at multiple levels, one of the few certainties is that nothing yet is certain.

\section{Pathophysiology}

The coronaviruses (CoVs) have become the most emerging pathogens of respiratory disease epidemics. Prior to the SARS-CoV-2 pandemic, two epidemics with CoVs have occurred during the past two decades, the SARS-CoV in 2003 and the Middle East respiratory syndrome coronavirus (MERS-CoV) in 2012 [6,7]. These viruses can cross species barriers and cause, in humans, illness ranging from mild upper 
respiratory infection to severe acute respiratory illness such as MERS and SARS. Indeed, person-to-person transmission of SARS-CoV-2 among close family contacts and coworkers, even without travel history, is the regular route for the infection $[6,7]$.

The CoVs are enveloped, positive-sense, single-stranded RNA viruses with nucleocapsid and a crown-like appearance under an electron microscope. The subfamily Orthocoronavirinae of the Coronaviridae family classifies into four genera of CoVs: Alphacoronavirus (alphaCoV), Betacoronavirus (betaCoV), Deltacoronavirus (deltaCoV), and Gammacoronavirus (gammaCoV) [7, 8]. The SARSCoV-2 belongs to the betaCoV genera, like MERS-CoV and SARS-CoV. To date, seven CoVs are known to infect humans and cause outbreaks with variable clinical severity [6-10].

Several sequences for SARS-CoV-2 have been published $[1,2,11]$. These resources allowed researchers to trace the phylogenetic tree and to recognize strains that vary according to the mutations $[12,13]$. For instance, a recent report by Angeletti et al. suggested that a spike mutation, which probably occurred in late November 2019, triggered crossing the species barriers to humans [12]. Moreover, the availability of the complete genome of SARS-CoV-2 allowed scientists to develop diagnostic laboratory tests $[14,15]$. The synthesis of viral polyprotein $1 \mathrm{a} / 1 \mathrm{ab}$ (pp1a/pp1ab) from the viral RNA is achieved in the host cells. In the SARS-CoV-2 genome, at least six ORFs can be generated. Specifically, a frameshift between ORF1a and ORF1b guides the production of both 1 a and $1 \mathrm{ab}$ polypeptides that are processed by virally encoded proteases for producing 16 nonstructural proteins (nsps). Other ORFs encode structural proteins, including spike (S), membrane $(\mathrm{M})$, envelope $(\mathrm{E})$, nucleocapsid proteins $(\mathrm{N})$, and accessory protein chains $[1,2,10,16]$ [Fig 1].

Evolving literature links virulence mechanisms of $\mathrm{CoVs}$, including SARS-CoV-2, to the nsps and structural proteins. For example, the nsps are able to block the host innate immunity [17], and the envelope (E) promotes viral assembly and release. In particular, more information is now available about the features of the spike glycoproteins positioned on the viral surface of CoVs, which guide the binding to host receptors and determine host tropism and transmission properties [12, $16,17]$. Each monomer of the trimeric S protein contains two subunits, S1 and S2, mediating attachment and membrane fusion, respectively. The S1 subunit utilizes human angiotensin-converting enzyme 2 (hACE2), an important regulator of the cardiovascular system, as the receptor to infect human cells [18-20]. Being highly conserved, S2 could be a selective target for antiviral (anti-S2) agents. In contrast, the spike receptor-binding domain presents only $40 \%$ amino acid identity with SARS-CoV. Other SARS-CoV-2-specific structural elements are the ORF3b and ORF8 that have no homology with those of SARS-CoV. Finally, the N protein plays an important role in viral replication. Research will be needed to further determine the structural components of SARS-CoV-2 that underlie the pathogenicity.

The pathogenic mechanism of COVID-19 disease is complex and poorly understood. Clinical longitudinal studies will have to elucidate the underlying mechanisms of the variety of clinical manifestations of this disease. The expression of ACE2 in the lower respiratory tract is believed to have determined the natural history of SARS tropism to infect the lower respiratory tract [20]. The available data indicate that SARSCoV-2 infection produces an uncontrolled immune response in the host, known as a "cytokine storm" [21]. The main culprit of this storm is interleukin 6 (IL-6) produced by activated leukocytes. IL-6 can execute different actions on a large number of cells and tissues. It also stimulates the production of acute phase proteins that play important roles in thermoregulation and can result in severe tissue damage and multi-organ dysfunction.

\section{Diagnostic testing for COVID-19}

\section{Sample collection}

Clinical and epidemiologic information have been used by most countries to determine who should be tested [22]. In the USA, diagnostic testing indications were limited at the beginning of the outbreak secondary to regulatory

Fig. 1 SARS-CoV-2 genome and structure
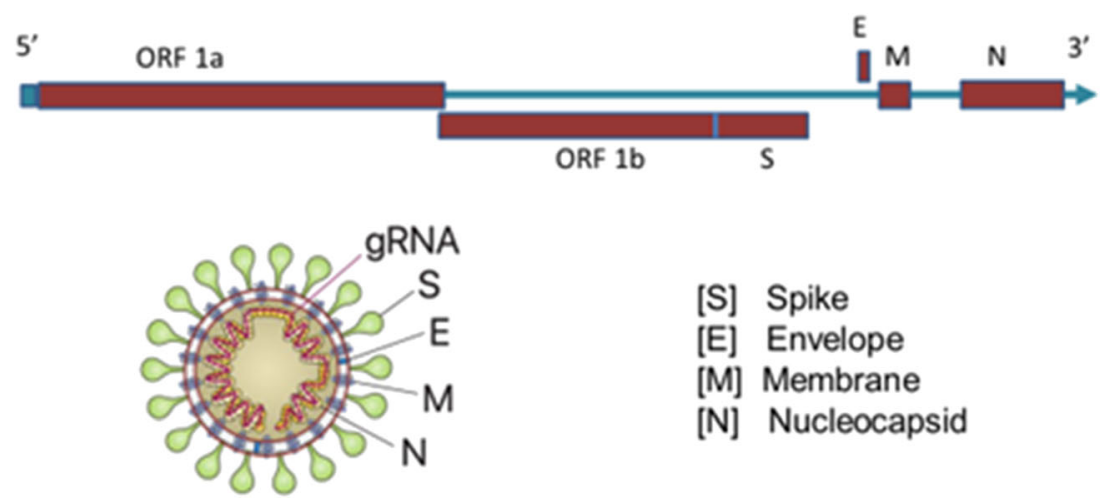

[S] Spike

[E] Envelope

[M] Membrane

[N] Nucleocapsid 
procedures for the new tests. Subsequently, the FDA released policies to allow laboratories to use their validated assays. On March 4, 2020, the Centers for Disease Control and Prevention (CDC) removed restrictive testing criteria, encouraging the clinicians to use their judgment to determine whether a test should be performed. At present, the CDC recommends two criteria for testing [23]. The high priority category includes hospitalized patients with symptoms, healthcare facility workers, and residents in long-term care facilities or other congregate living settings with symptoms. The priority category includes persons with symptoms of suspected COVID-19 infection and persons without symptoms who are prioritized by healthcare providers, for any reason, including public health monitoring or screening according to state and local plans. The CDC does not recommend testing for asymptomatic persons.

Once a person is identified as a person under investigation (PUI) for COVID-19, it is recommended that the clinician should immediately adapt infection control and prevention (PPE) measures. In addition to excluding all other sources of respiratory infection, the decision on who to test should be based on the CDC guidance and local epidemiological data. For sampling, the WHO recommends collecting specimens from both the upper respiratory tracts, nasopharyngeal (NP) and oropharyngeal (OP) swabs, in the spontaneously breathing patients, and the lower respiratory tract in the mechanically ventilated patients. Researchers have proven that NP swab specimen is superior to the OP swab specimen for the examination of SARS-CoV-2 $[24,25]$ as higher viral loads were detected in the nasal area than in the throat [26]. Therefore, NP swab is the preferred sampling method for COVID-19 diagnosis. Upon collection, the swabs should be placed immediately into a sterile transport tube containing $2-3 \mathrm{~mL}$ of either viral transport medium (VTM), Amies transport medium, or sterile saline [27] and stored at $4{ }^{\circ} \mathrm{C}$. Potential risks of NP swabs include (1) the production of aerosol during the sampling, which can impose infection risks to healthcare workers; (2) the inconsistent quality of NP swabs between collections, which may lead to false-negative results; and (3) the patient may experience discomfort during the sampling procedure. Aiming to address these potential risks, further studies demonstrated the efficacy of less invasive routes for sampling such as throat wash and sputum collection [25-30]. Saliva collection was shown to yield greater detection sensitivity and consistency throughout the course of the infection when compared with patient-matched NP samples. Furthermore, saliva could enable self-administered sample collection for accurate large-scale SARS-CoV-2 testing [28]. Some authors suggested a potential value in testing both fecal and respiratory specimens to improve the test sensitivity [29]. However, this issue remains under debate, as the detection of viral RNA in stool may not reflect actual viral replication or infection [30].

\section{Developing diagnostic tests for COVID-19}

\section{SARS-CoV-2 nucleic acid testing (NAT)}

The top priority for controlling the rapidly evolving SARSCoV-2-associated-COVID-19 is developing a diagnostic test of high performance. The use of viral culture is not feasible option for rapid diagnosis as it takes 3-5 days for SARS-CoV2 to cause obvious cytopathic changes in vitro. In addition, virus isolation requires biosafety level-3 (BCL-3) facilities of limited availability in many medical centers. Serology tests have not yet been validated. Moreover, the issue of crossreactivity with SARS-CoV remains to be solved. Therefore, at present, a positive result in nucleic acid testing (NAT) using reverse transcription-polymerase chain reaction (RT-PCR) is the gold standard for diagnosing COVID-19 [14, 31, 32]. Although the assay is highly specific, the sensitivity is relatively low secondary to several factors including the viral load, virus replication, RNA isolation method, and the source and timing of swab collection in relation to the disease stage [33]. Therefore, further optimization to mitigate the high falsenegative rate has been a crucial goal of high priority.

After collection, the clinical samples are subjected to RNA isolation. This is a time-consuming step that is also extremely important to avoid the false-negative results. The optimal protocol for the isolation of RNA would ideally provide pure RNase-free nucleic acid and recover RNA quantitatively across a range of dilutions. Several protocols for RNA isolation have been used by different laboratory. The efficiency of RNA isolation protocols for SARS-CoV-2 from stool samples was discussed in a recent multicenter study [34]. However, limited data are currently available regarding the performance of RNA extraction methods from other different types of specimens.

After RNA isolation from the clinical sample and amplification through a reverse transcription polymerase chain reaction (RT-PCR), the SARS-CoV-2-specific primers serve to search for the viral RNA sequences that are conserved [35]. In patients with confirmed COVID-19 diagnosis, the laboratory evaluation should be repeated to confirm viral clearance prior to releasing from isolation [36]. The conserved or abundantly expressed genes such as the structural genes $\mathrm{N}$ and $\mathrm{E}$ and the nonstructural RNA-dependent RNA polymerase (RdRp) as well as the ORF $1 \mathrm{a} / \mathrm{b}$ genes are the preferred targets for the SARS-CoV-2 RT-PCR assays [12, 16]. Traditionally, two molecular targets should be included in the assay to avoid potential cross-reaction with other $\mathrm{CoVs}$ as well as potential genetic drift of SARS-CoV-2. Among these assays, the RdRp assay exhibited the highest sensitivity (3.8 RNA copies/reaction at $95 \%$ detection probability) and involves two probes. One of the probes is non-specific, which would detect other CoVs, whereas the second probe is specific for the SARS-CoV-2. These RdRp assays have been used in $>30$ 
laboratories in Europe [15, 37]. In the USA, the CDC recommends assays targeting two nucleocapsid proteins [N1 and N2] [38], while the WHO recommends an initial screening with the E gene assay followed by a confirmatory assay using the RdRp gene [15]. Importantly, the RdRp assays were designed and validated using synthetic nucleic acid technology (in vitro transcription) in the absence of SARS-CoV-2 isolates or patient specimens [16].

Given high false-negative rates, additional studies on COVID-19 samples highlighted the importance of successive sampling and testing of SARS-CoV-2 by RT-PCR [39]. Yuan et al. reported that PCR assays returned positive in 25 COVID-19 patients after discharge [40]. Therefore, repeated viral RT-PCR testing separated by $48 \mathrm{~h}$ is essential. In addition, other parameters (D-dimer and absolute lymphocyte count, etc.) should be combined with negative RT-PCR test as additional measures to assure that recovered patients can be released from isolation. The protocols of several RT-PCR assays have been implemented and published online (https:// www.who.int/emergencies/diseases/novel-coronavirus-2019/ technical-guidance/laboratory-guidance). One of these assays is the reverse transcripton loop-mediated isothermal amplification assays, known as RT-LAMP, which were developed by Park GS et al. These assays were designed to detect SARS-CoV-2 specifically even at low copy numbers, without detecting other human CoVs. Furthermore, a colorimetric detection method was developed for this assay allowing its potential use at higher throughput [41].

More recently, Chan JF et al. developed novel RT-PCR assays for COVID-19 targeting a different sequence of the RdRp/ Hel (helicase/hemagglutinin-esterase (HE) [42]. The researchers validated these assays using both in vitro system and samples from patients with confirmed diagnosis of COVID-19. The new RdRp/Hel assay exhibited higher sensitivity and specificity without cross-reactivity with other common respiratory viruses. The authors speculated that the new $\mathrm{RdRp} / \mathrm{Hel}$ assay might be employed for detecting COVID-19 cases with low viral loads, particularly when samples from the upper respiratory tract, saliva, or plasma are used for testing. Moreover, they proposed using these assays for serial monitoring of the viral load in plasma of the COVID-19 patients to detect the cases with SARS-CoV-2 RNAemia (circulating viral RNA in blood) and, thereby, to inform prognostic and treatment decisions.

\section{Serology testing for SARS-CoV-2 antibodies}

Serologic assays are urgently needed for (1) infection prevention measures including identifying the viral sources; (2) epidemiologic and sero-surveillance studies to infer the burden of disease, taking into account the rate of asymptomatic infection and the extent disease transmission to the households; and (3) analyzing the results of vaccine trials and therapeutic antibodies. However, other than few exceptions [43], validated serologic assays are relatively lacking at present.

The lateral flow assays for SARS-CoV-2 IgM and IgG antibodies may potentially be useful in assessing the burden of COVID-19 infection. However, important limitations exist, including the low specificity of the IgM responses and the delayed seroconversion of the specific IgG responses. Therefore, these assays cannot be used for acute diagnostics but may represent an indirect indication of COVID-19 infection that is best utilized to confirm late COVID-19 cases, retrospectively, or to assess the immunity of healthcare providers during the pandemic. In addition, they can be useful to predict which patient would benefit from repeat testing, selfisolation, or targeted therapies for COVID-19 [43, 44]. Finally, it should be noted that convalescent plasma, or immunoglobulin-containing fractions, obtained from recovered COVID-19 cases have been successfully used to treat patients with active COVID-19 disease [45, 46].

The spike and nucleocapsid proteins are the main immunogens of the SARS-CoV-2 [6]. Okba NMA et al. established serologic assays for detection of SARS-CoV-2 neutralizing, spike protein-specific (S), and nucleocapsid-specific (N) antibodies using serum samples from patients with PCRconfirmed SARS-CoV-2 infection [47]. The investigators validated the various antigens using ELISA platforms and found that most of the patients with the SARS-CoV-2 infection seroconverted by 2 weeks after the beginning of their illness. Particularly, the S1 subunit was more specific than S2 in detecting the SARS-CoV-2-specific antibodies. This finding could be explained by the higher conservation of the S2 subunit in CoVs, relative to S1. Therefore, $\mathrm{S} 1$ was identified as a specific antigen for the SARS-CoV-2 serology testing. Remarkably, further validation of S1-specific IgA and $\operatorname{IgG}$ ELISA assays by two different groups revealed that while the IgA-based ELISA was more sensitive, the IgG ELISA showed higher specificity than the IgA ELISA. Furthermore, compared with $\operatorname{IgA}, \operatorname{IgG}$ is longer lasting in patients and thus is preferred for serology studies. To date, no studies have addressed cross-reactivity from other non-specific proteins that can lead to false-positive result. Further studies and optimization of ELISA assays will be necessary.

The frequency of detecting antibodies to the $\mathrm{N}$ protein in COVID-19 patients indicates that the $\mathrm{N}$ protein may be useful as an immunodominant antigen in the early diagnosis of COVID-19 disease [48-50]. For testing antibodies to the $\mathrm{N}$ protein, investigators relied on the high degree of similarity between the SARS-CoV and SARS-CoV-2 proteins (estimated $90 \%$ ) to develop a new ELISA assay, in which the SARS$\mathrm{CoV} \mathrm{N}$ protein was used as antigen. Using 3 different validated ELISAs, the investigators demonstrated that higher antibody levels are associated with the severity of infection. Furthermore, they showed that $\mathrm{N}$-specific IgG seroconversion occurs in the second week after the beginning of the 
symptoms. Remarkably, compared with S1 ELISAs, the N protein ELISAs showed higher sensitivity in detecting antibodies in mildly infected patients and stronger correlations with the plaque reduction neutralization test. However, this observation requires confirmation in a larger cohort of patients with different levels of disease severity to precisely monitor the timing of seroconversion even in mildly symptomatic patients. Further, antibodies against two different antigens should be tested to decrease false-negative results in serial disease monitoring studies [51]. Well-defined standard references should be developed to standardize the serologic assays developed by different laboratories, to account for inter-assay variability, and to unify data interpretation tools from different studies. Finally, as research efforts are currently focused on developing a vaccine for SARS-CoV-2, validation and standardization of serologic testing are crucial for evaluating vaccine immunogenicity and effective induction of antibody responses for prevention.

\section{Rapid antigen detection assays}

Rapid antigen assays are emerging new class of tests to be used in the SARS-CoV-2 pandemic. These assays are designed to detect particles of the viral proteins in nasal swabs quickly by using simple qualitative or semiquantitative in vitro diagnostic procedure, which can be performed either in the lab or at a local point of care to give results within $1 \mathrm{~h}$ [52]. Rapid antigen assays are currently being validated to enhance clinical laboratories' capacity to match the urgent need for rapid COVID-19 detecting in response to the pandemic. The first emergency used authorization has been issued by the US Food and Drug Administration (FDA) to the Quidel Corporation for the Sofia 2 SARS Antigen FIA on May11, 2020 [53]. This test is authorized for use in CLIA (Clinical Laboratory Improvement Amendments) certified laboratories. Few other rapid tests are currently being validated by the WHO or on the FDA list. An important advantage of an antigen test is the speed of the test at lower cost and the high specificity. However, they have high false-negative rate due to lower sensitivity. Therefore, a negative result from a rapid antigen test requires confirmation with a PCR test prior to formalizing isolation and treatment decisions.

\section{Other molecular laboratory tests}

As mentioned previously, the main culprit of the uncontrolled excessive immune reaction to SARS-CoV-2 is IL6 , which was found to increase, particularly during the symptomatic exacerbation of COVID-19 disease. Other common molecular laboratory findings in the early stage of COVID-19 disease include decreased white blood cells, lymphocytes, and platelets as well as metablic acidosis with elevated lactate dehydrogenase (LDH), elevated liver transaminases, muscle enzymes, and reactive protein C. In addition, laboratory indicators of systemic shock, ARDS, and disseminated intravascular coagulopathy have been reported in the severely ill patients. Notably, lymphopenia and elevated LDH appear to be negative prognostic factors, while procalcitonin value has been reported to be normal in several COVID-19 cohorts [21, 54]. Other than the descriptive data obtained from retrospective analysis of COVID-19 patients' clinical records, the current literature is lacking the pathogenic mechanisms. Clinical, preclinical, and pathological research will have to elucidate the pathophysiology underlying the various manifestations of the disease.

\section{The role of chest imaging in COVID-19 diagnosis}

The pathomechanisms of pneumonia in COVID-19 disease are poorly understood. Data available from histopathological slides indicate pulmonary edema, of primary respiratory origin, and thick proteinaceous exudates consisting of large protein globules associated with hyperplasia of the pneumocytes. Additionally, vascular engorgement and interstitial inflammatory process, involving fibrinoid material and multinucleated tissue macrophages, have been reported [55].

Current literature evidence indicates that $60-93 \%$ of patients have positive chest computed tomographic (CT) findings consistent with COVID-19 infection prior to positive RT-PCR test results [56, 57]. The pulmonology findings on chest $\mathrm{CT}$ images are more prominent approximately 10 days after the onset of the disease, including bilateral pneumonia noted in $80 \%$ of cases. Other lung abnormalities include ground glass opacities and lobular wall thickening. Notably, progressive consolidation can take place up to 2 weeks, while fibrotic bands were recognized upon the resolution of symptoms. In addition, reactive lymphadenopathy that resolved within 1 month was noted in some cases. Remarkably, any of these radiology findings were reported to change dynamically over a short period of time.

In light of high false-negative result rate in nucleic acid testing (NAT) using RT-PCR technology, thoracic CT imaging has become a critical diagnostic tool, in combination with close monitoring of clinical features and epidemiological data for COVID-19 confirmation and management. More recently, Fang et al. reported that the sensitivity of CT (98\%) exceeded that of RT-PCR (71\%) in diagnosing COVID-19 [56]. Therefore, several reports suggested that the suspected COVID-19 patient (PUI) should not be prematurely cleared from quarantine and PPE measures should not be discontinued by one negative result of RT-PCR testing [56, 57]. Rather, the patient's symptoms, chest $\mathrm{CT}$ images, and other laboratory parameters should be taken into account to inform the clinical decision regarding further management, 
PPE measures, and evaluating the need for repeating the diagnostic test. Although several studies described the imaging features of COVID-19, clinical stratification of pulmonology abnormalities and their correlation with the disease course need to be conducted in the future. Such data may lead to identification of a prognostic matrix for the disease.

\section{Concluding remarks}

Incredible efforts are being made to contain a global crisis that is aggressively testing the healthcare systems worldwide. Infection prevention and control officers are tasked at maximum capacities to flatten the curve of COVID-19 spread. Clinicians are intensely challenged with limited therapeutic options and specific targets for this disease. Scientists are at full speed to develop diagnostic testing, vaccines, and new therapies.

Laboratory investigations to determine the structural elements of SARS-CoV-2 that underlie its pathogenicity are needed to identify diagnostic and therapeutic targets. Longitudinal clinical and preclinical studies will be tasked to explain the heterogenous clinical manifestation of the COVID-19 disease. Prospective longitudinal studies and clinical trials will be necessary to understand the disease epidemiology and clinical course and to evaluate potential vaccines for prevention and efficacy of specific therapies.

It must be acknowledged that this overview is based on initial clinical and scientific reports. To date, there is paucity of information regarding the impact on the cardiovascular system and congenital heart defects population [58]. Current therapeutic approaches to deal with the infection are mainly symptomatic and basic life support measures. Prevention aimed at reducing human-to-human transmission remains our best option.

Acknowledgment The author acknowledges Dr. Aldons J. Lusis for his critical review of the manuscript.

Authors' contributions MT Conceived and wrote the manuscript.

\section{Compliance with ethical standards}

Conflict of interest The author declares that she has no conflicts of interest.

\section{References}

1. Chen L, Liu W, Zhang Q, Xu K, Ye G, Wu W, Sun Z, Liu F, Wu K, Zhong B, Mei Y, Zhang W, Chen Y, Li Y, Shi M, Lan K, Liu Y (2020) RNA based mNGS approach identifies a novel human coronavirus from two individual pneumonia cases in 2019 Wuhan outbreak. Emerg Microbes Infect 9(1):313-319
2. Zhu N, Zhang D, Wang W, Li X, Yang B, Song J, Zhao X, Huang B, Shi W, Lu R, Niu P, Zhan F, Ma X, Wang D, Xu W, Wu G, Gao GF, Tan W (2020) A novel coronavirus from patients with pneumonia in China, 2019. N Engl J Med 382(8):727-733

3. Jiang S, Du L, Shi Z (2020) An emerging coronavirus causing pneumonia outbreak in Wuhan, China: calling for developing therapeutic and prophylactic strategies. Emerg Microbes Infect 9(1): 275-277

4. Guan WJ, Zhong NS (2020) Letter from China. Respirology 25(6): $657-658$

5. https://www.google.com/search?sxsrf=ALeKk03CS16RzZv2d4WNLT2UeCH7MSOMA:1589689664696\&q=covid+19+ case+count+worldwide

6. Li Q, Guan X, Wu P, Wang X, Zhou L, Tong Y, Ren R, Leung KSM, Lau EHY, Wong JY, Xing X, Xiang N, Wu Y, Li C, Chen Q, Li D, Liu T, Zhao J, Liu M, Tu W, Chen C, Jin L, Yang R, Wang Q, Zhou S, Wang R, Liu H, Luo Y, Liu Y, Shao G, Li H, Tao Z, Yang Y, Deng Z, Liu B, Ma Z, Zhang Y, Shi G, Lam TTY, Wu JT, Gao GF, Cowling BJ, Yang B, Leung GM, Feng Z (2020) Early transmission dynamics in Wuhan, China, of novel coronavirus-infected pneumonia. N Engl J Med 382(13):1199-1207

7. Chan JF, Yuan S, Kok KH, To KK, Chu H et al (2020) A familial cluster of pneumonia associated with the 2019 novel coronavirus indicating person-to-person transmission: a study of a family cluster. Lancet 395(10223):514-523

8. Perlman S, Netland J (2009) Coronaviruses post-SARS: update on replication and pathogenesis. Nat Rev Microbiol 7(6):439-450

9. Woo PC, Lau SK, Lam CS, Lau CC, Tsang AK et al (2012) Discovery of seven novel mammalian and avian coronaviruses in the genus deltacoronavirus supports bat coronaviruses as the gene source of alphacoronavirus and betacoronavirus and avian coronaviruses as the gene source of gammacoronavirus and deltacoronavirus. J Virol 86:3995-4008

10. Cascella M, Rajnik M, Cuomo A, Dulebohn SC, Di Napoli R (2020-2020) Features, evaluation and treatment coronavirus (COVID-19). StatPearls Publishing

11. Woo PC, Huang Y, Lau SK, Yuen KY (2010) Coronavirus genomics and bioinformatics analysis. Viruses 2(8):1804-1820

12. Lu R, Zhao X, Li J, Niu P, Yang B, Wu H, Wang W, Song H, Huang B, Zhu N, Bi Y, Ma X, Zhan F, Wang L, Hu T, Zhou H, Hu Z, Zhou W, Zhao L, Chen J, Meng Y, Wang J, Lin Y, Yuan J, Xie Z, Ma J, Liu WJ, Wang D, Xu W, Holmes EC, Gao GF, Wu G, Chen W, Shi W, Tan W (2020) Genomic characterization and epidemiology of 2019 novel coronavirus implications for virus origins and receptor binding. Lancet 395(10224):565-574

13. Angeletti S, Benvenuto D, Bianchi M, Giovanetti M, Pascarella S, Ciccozzi M (2020) COVID-2019: the role of the nsp2 and nsp3 in its pathogenesis. J Med Virol

14. Chu DKW, Pan Y, Cheng SMS, Hui KPY, Krishnan P, Liu Y, Ng DYM, Wan CKC, Yang P, Wang Q, Peiris M, Poon LLM (2020) Molecular diagnosis of a novel coronavirus (2019-nCoV) causing an outbreak of pneumonia. Clin Chem 66(4):549-555

15. Corman VM, Landt O, Kaiser M, Molenkamp R, Meijer A et al (2020) Detection of 2019 novel coronavirus (2019-nCoV) by realtime RT-PCR. Euro Surveill 25(3):2000045

16. Cui J, Li F, Shi ZL (2019) Origin and evolution of pathogenic coronaviruses. Nat Rev Microbiol 17(3):181-192

17. Lei J, Kusov Y, Hilgenfeld R (2018) Nsp3 of coronaviruses: structures and functions of a large multi-domain protein. Antivir Res 149:58-74

18. Song W, Gui M, Wang X, Xiang Y (2018) Cryo-EM structure of the SARS coronavirus spike glycoprotein in complex with its host cell receptor ACE2. PLoS Pathog 14(8):e1007236

19. Liu PP, Blet A, Smyth D, Li H (2020) The science underlying COVID-19: implications for the cardiovascular system. Circulation 
20. Bao L, Deng W, Huang B, Gao H, Liu J et al (2020) The pathogenicity of SARS-CoV-2 in hACE2 transgenic mice. Nature

21. Huang C, Wang Y, Li X, Ren L, Zhao J, Hu Y, Zhang L, Fan G, Xu J, Gu X, Cheng Z, Yu T, Xia J, Wei Y, Wu W, Xie X, Yin W, Li H, Liu M, Xiao Y, Gao H, Guo L, Xie J, Wang G, Jiang R, Gao Z, Jin Q, Wang J, Cao B (2020) Clinical features of patients infected with 2019 novel coronavirus in Wuhan, China. Lancet 395(10223):497506

22. World Health Organization (2020) Laboratory testing for coronavirus disease (COVID-19) in suspected human cases. Ref: WHO/ COVID-19/laboratory/2020.5. World Health Organization, Geneva

23. Center for Disease control and Prevention (CDC). Evaluating and testing persons for coronavirus disease 2019 (COVID-19). https:// www.cdc.gov/coronavirus/2019-nCoV/hcp/clinical-criteria.html. Accessed 27 May 2020

24. Zou L, Ruan F, Huang M, Liang L, Huang H, Hong Z, Yu J, Kang M, Song Y, Xia J, Guo Q, Song T, He J, Yen HL, Peiris M, Wu J (2020) SARS-CoV-2 viral load in upper respiratory specimens of infected patients. N Engl J Med 382:1177-1179

25. Wang W, Xu Y, Gao R, Lu R, Han K et al (2020) Detection of SARS-CoV-2 in different types of clinical specimens. JAMA

26. Kim C, Ahmed JA, Eidex RB, Nyoka R, Waiboci LW, Erdman D, Tepo A, Mahamud AS, Kabura W, Nguhi M, Muthoka P, Burton W, Breiman RF, Njenga MK, Katz MA (2011) Comparison of nasopharyngeal and oropharyngeal swabs for the diagnosis of eight respiratory viruses by real-time reverse transcription-PCR assays. PLoS One 6:e21610

27. Center for Disease control and Prevention (CDC). Interim guidelines for collecting, handling, and testing clinical specimens from persons for coronavirus disease 2019 (COVID-19). https://www. cdc.gov/coronavirus/2019-nCoV/lab/guidelines-clinicalspecimens.html. Accessed 27 May 2020

28. Wyllie AL, Fournier J, Casanovas-Massana A, Campbell C, Tokuyama M et al Saliva is more sensitive for SARS-CoV-2 detection in COVID-19 patients than nasopharyngeal swabs. https:// doi.org/10.1101/2020.04.16.20067835

29. Tian Y, Rong L, Nian W, He Y (2020) Gastrointestinal features in COVID-19 and the possibility of faecal transmission. Aliment Pharmacol Ther 51(9):843-851

30. Lo IL, Lio CF, Cheong HH, Lei CI, Cheong TH, Zhong X, Tian Y, Sin NN (2020) Evaluation of SARS-CoV-2 RNA shedding in clinical specimens and clinical characteristics of 10 patients with COVID-19 in Macau. Int J Biol Sci 16(10):1698-1707

31. Loeffelholz MJ, Tang YW (2020) Laboratory diagnosis of emerging human coronavirus infections - the state of the art. Emerg Microbes Infect 9:747-756

32. Emery SL, Erdman DD, Bowen MD, Newton BR, Winchell JM, Meyer RF, Tong S, Cook BT, Holloway BP, McCaustland KA, Rota PA, Bankamp B, Lowe LE, Ksiazek TG, Bellini WJ, Anderson LJ (2004) Real-time reverse transcription-polymerase chain reaction assay for SARS-associated coronavirus. Emerg Infect Dis 10:311-316

33. Wölfel R, Corman VM, Guggemos W, Seilmaier M, Zange S, Müller MA, Niemeyer D, Jones TC, Vollmar P, Rothe C, Hoelscher M, Bleicker T, Brünink S, Schneider J, Ehmann R, Zwirglmaier K, Drosten C, Wendtner C (2020) Virological assessment of hospitalized patients with COVID-2019. Nature 581:465469

34. Petrich A, Mahony J, Chong S, Broukhanski G, Gharabaghi F, Johnson G, Louie L, Luinstra K, Willey B, Akhaven P, Chui L, Jamieson F, Louie M, Mazzulli T, Tellier R, Smieja M, Cai W, Chernesky M, Richardson SE, for the Ontario Laboratory Working Group for the Rapid Diagnosis of Emerging Infections (2006) Multicenter comparison of nucleic acid extraction methods for detection of severe acute respiratory syndrome coronavirus RNA in stool specimens. J Clin Microbiol 44(8):2681-2688
35. Zhang YZ. Novel 2019 coronavirus genome. http://virological.org/ t/novel-2019-coronavirus-genome/319. Accessed 27 May 2020

36. Lv DF, Ying QM, Weng YS, Shen CB, Chu JG, Kongc J-p, Sunc D-h, Gaog X, Weng X-b, Cheni X-q (2020) Dynamic change process of target genes by RT-PCR testing of SARS-Cov-2 during the course of a coronavirus disease 2019 patient. Clin Chim Acta 506: $172-175$

37. Goff J, Rowe A, Brownstein JS, Chunara R (2015) Surveillance of acute respiratory infections using community-submitted symptoms and specimens for molecular diagnostic testing. PLoS Curr 7: ecurrents

38. Holshue ML, DeBolt C, Lindquist S, Lofy KH, Wiesman J, Bruce H, Spitters C, Ericson K, Wilkerson S, Tural A, Diaz G, Cohn A, Fox L, Patel A, Gerber SI, Kim L, Tong S, Lu X, Lindstrom S, Pallansch MA, Weldon WC, Biggs HM, Uyeki TM, Pillai SK, Washington State 2019-nCoV Case Investigation Team (2020) First case of 2019 novel coronavirus in the United States. N Engl J Med 382:929-936

39. Tolia VM, Chan TC, Castillo EM (2020) Preliminary results of initial testing for coronavirus (COVID-19) in the emergency department. West J Emerg Med 21(3):503-506

40. Yuan J, Kou S, Liang Y, Zeng J, Pan Y, Liu L (2020) PCR assays turned positive in 25 discharged COVID-19 patients. Clin Infect Dis

41. Park GS, Ku K, Baek SH, Kim SJ, Kim SI et al (2020) Development of reverse transcription loop-mediated isothermal amplification (RT-LAMP) assays targeting SARS-CoV-2. J Mol Diagn 22(6):729-735

42. Chan JF, Yip CC, To KK, Tang TH, Wong SC et al (2020) Improved molecular diagnosis of COVID-19 by the novel, highly sensitive and specific COVID-19-RdRp/Hel real-time reverse transcription-polymerase chain reaction assay validated in vitro and with clinical specimens. J Clin Microbiol 58(5):e00310-20

43. Pulia MS, O'Brien TP, Hou PC, Schuman A, Sambursky R (2020) Multi-tiered screening and diagnosis strategy for COVID-19: a model for sustainable testing capacity in response to pandemic. Ann Med 14:1-8

44. Casadevall A, Pirofski LA (2020) The convalescent sera option for containing COVID-19. J Clin Invest 130(4):1545-1548

45. Zhang W, Du RH, Li B, Zheng XS, Yang XL et al (2020) Molecular and serological investigation of 2019-nCoV infected patients: implication of multiple shedding routes. Emerg Microbes Infect 9:386-389

46. Chen X, Zhou B, Li M, Liang X, Wang H et al (2020) Serology of severe acute respiratory syndrome: implications for surveillance and outcome. J Infect Dis 189:1158-1163

47. Okba NMA, Müller MA, Li W, Wang C, GeurtsvanKessel CH et al (2020) Severe acute respiratory syndrome coronavirus $2-$ specific antibody responses in coronavirus disease 2019 Patients. Emerg Infect Dis 26(7)

48. Chan-Yeung M, Xu RH (2003) SARS: epidemiology. Respirology 8(Suppl):S9-S14

49. Liu Y, Eggo RM, Kucharski AJ (2020) Secondary attack rate and superspreading events for SARS-CoV-2. Lancet 395(10227):e47

50. Guo L, Ren L, Yang S, Xiao M, Chang D et al (2020) Profiling early humoral response to diagnose novel coronavirus disease (COVID-19). Clin Infect Dis

51. Li Z, Yi Y, Luo X, Xiong N, Liu Y et al (2020) Development and clinical application of a rapid IgM-IgG combined antibody test for SARS-CoV-2 infection diagnosis. J Med Virol

52. European Centre for disease Prevention and Control (2020) An overview of the rapid test situation for COVID-19 diagnosis in the EU/EEA. European Centre for disease Prevention and Control, Stockholm https://www.ecdc.europa.eu/sites/default/files/ documents/Overview-rapid-test-situation-for-COVID-19diagnosis-EU-EEA. Accessed 27 May 2020 
53. Shuren JE FDA Statement. Coronavirus (COVID-19) update: FDA authorizes first antigen test to help in the rapid detection of the virus that causes COVID-19 in patients. https://www.fda.gov/newsevents/press-announcements/coronavirus-covid-19-update-fdaauthorizes-first-antigen-test-help-rapid-detection-virus-causes. Accessed 27 May 2020

54. Wu Z, McGoogan JM (2020) Characteristics of and important lessons from the coronavirus disease 2019 (COVID-19) outbreak in China: summary of a report of 72314 cases from the Chinese center for disease control and prevention. JAMA

55. Tian $\mathrm{S}, \mathrm{Hu}$ W, Niu L, Liu H, Xu H, Xiao SY (2020) Pulmonary pathology of early-phase 2019 novel coronavirus
(COVID-19) pneumonia in two patients with lung cancer. J Thorac Oncol

56. Fang Y, Zhang H, Xie J, Lin M, Ying L et al (2020) Sensitivity of chest CT for COVID-19: comparison to RT-PCR. Radiology 200432

57. Chen X, Tang Y, Mo Y, Li S, Lin D et al (2020) A diagnostic model for coronavirus disease 2019 (COVID-19) based on radiological semantic and clinical features: a multi-center study. Eur Radiol 1-10

58. Foo R, Wang Y, Zimmermann WH, Backs J, Wang DW (2020) Cardiovascular molecular mechanisms of disease with COVID-19. J Mol Cell Cardiol 141:107

Publisher's note Springer Nature remains neutral with regard to jurisdictional claims in published maps and institutional affiliations. 